\title{
Estimation of Ventilation stream dynamics and tunnel geometry affect over the evacuation period adjusted to the model of motorcar tunnel in case of modelled fires
}

\author{
T. Kunchulia ${ }^{1}$, Z. Khokerashvili ${ }^{1}$, N. Arudashvili ${ }^{1}$, Z. Lanchava ${ }^{1}$ \\ ${ }^{I}$ Georgian Technical University, Tbilisi, Georgia
}

The quality of the motorcar tunnels operation is determined according to its safety for which, every single danger should be identified and the volume of risk consequently evaluated. The volume of risk arisen from existing danger depends on heavy results from dangerous action and the probability of possible dangerous action.

Due to certain reasons, one of the dangers in motorcar tunnel is considered initiation and spreading the fire. The fire initiated and increasing in such space features few damaging factors: great volume of heat formed during the burning process of inflammable material influencing basic infrastructure and toxic products, released from incomplete burn influencing human vitality.

Upon the possible arrival of such circumstances, the supreme priority is to save human lives; at that moment, the only right move is to perform timely and organized self-evacuation from the risk zone. While the self - evacuation can be completed since the moment of fire initiation till the collapse of ventilation system. Overall, the time of evacuation significantly depends on the opportunity of spreading the burnt products throughout the tunnel.

As commonly known, the burnt products, formed from the absence of multiple ventilation flows in the horizontal tunnel, shall be spread in both directions of the tunnel, while in case of longitudinal ventilation flow, most part of the burnt shall spread towards the stream direction, however, the less part of it shall be spread in the opposite direction of the tunnel, as long as the speed of spreading burnt products exceeds the critical speed of the ventilation flow. Moreover, spreading the burnt products has also the great influence over the length of reversal ventilation flow.

With bending tunnel, spreading burnt gases is asymmetric, due to the high temperature of burning material, less firmness and the "floating", thus caused. Apart from the given factors, spreading the burnt products are also affected with gradient factors. Determination of correlation among each factor with spreading burnt material under such circumstances is quite important.

The report focuses on one of the motorcar tunnel models created in terms of the grant provided by the Shota Rustaveli National Scientific Foundation. It specifically refers to the model of operating motorcar tunnel in which the fire, initiated and developed can be modelled at the decreased scale.

Amendment can be possible in ventilation air flows, pressure, bending of the tunnel angle as well as in other specifications therefore, determining regularity of burning products distribution according to critical speed of ventilation flow, reversal length, gradient factor and other characteristic specifications shall also be 
permitted considering the influence of transformable systems and elements as well as without consideration of those factors.

Moreover, there is numerical modelling of fires also planned for further respective modelling of motorcar tunnels, considering specific characteristics of tunnels geometry and aerodynamics of ventilation flows upon which, corresponding conclusions shall be made based on the obtained results.

\section{Acknowledgements}

This work was supported by Shota Rustaveli National Science Foundation (SRNSF) [Grant number AR-19-1936, Project title "Development and testing of transformable system to save life in road tunnel in case of fire"].

\section{REFERENCES}

1. O. Lanchava, E. Medzmariashvili, N. Ilias, G. Khitalishvili, Z. Lebanidze. Prospects of usage of transforming systems for extinguishing fire in tunnels. International Scientific Conference "Advanced Lightweight Structures and Reflector Antennas", Tbilisi, 2009, pp. 302-308.

2. O. Lanchava, N. Ilias, G. Nozadze. Some problems for assessment of fire in road tunnels. Quality Access to Success, Vol. 18, S1,2017, pp. 69-72.

3. N. Ilias, O. Lanchava, G. Nozadze. Numerical modelling of fires in road tunnels with longitudinal ventilation system. Quality Access to Success, Vol. 18, S1, 2017, pp. 7780 